\title{
Fragmentation in the Genus Autolytus and in other Syllids.
}

\author{
By
}

\author{
E. J. Allen, D.Sc., F.R.S.,
}

Director of the Plymouth Laboratory.

With 1 Figure in the Text.

In a former paper (Allen, Phil. Trans. Roy. Soc. B., Vol. 211, p. 131, 1921) it was shown that the Syllid Procerastea Halleziana Malaquin, in addition to the ordinary mode of sexual reproduction which occurs in this group, reproduced asexually by a process of fragmentation, followed by the regeneration by each fragment of a new head and series of anterior segments and of a new pygidium and posterior segments. The fragments usually consisted of sections of two, three, or four segments each, in the region of the body behind the seventh setigerous segment. It was further shown that this breaking up of Procerastea, which could be produced artificially at any time by treating the worms with sea-water of low salinity, made by adding distilled water to natural sea-water, took place according to a definite law. The first section consisted normally of the head and setigerous segments 1 to 7 , then followed three sections of two segments each (Segments 8 and $9 ; 10$ and $11 ; 12$ and 13 ), then three sections of three segments $(14-16 ; 17-19 ; 20-22)$, followed by four or five sections of four segments each, and then a number of sections of three segments. This was expressed as a formula thus :-

$$
\mathrm{H} 7+2+2+2+3+3+3+4+4+4+4(+4)+3+3+3+3+\ldots \mathrm{P}
$$

where $\mathrm{H}$ represents the head, $\mathrm{P}$ the pygidium or tail, and the plus sign the position at which a break occurs. A considerable number of segments at the posterior end do not break up readily and often not at all, these being young segments recently developed.*

* Previous to the publication of my paper on Procerastea, Mesnil and Caullery, in a paper entitled "Sur un processus normal de fragmentation, suivie de régénération, chez une Annélide Polychète, Syllis gracilis Gr." (Comptes rendus, t. 169, 1919, p. 926), which I had unfortunately overlooked, had described fragmentation followed by regenera. tion in Syllis gracilis. This case is described further in Mesnil, "Titres et travaux scientifiques (1893-1920)," Laval, Barnéoud, p. 37, and Mesnil et Caullery, "Sur la complexité du cycle évolutif des Annélides polychètes" (Comptes rendus, t. 178, 1924, p. 168). They did not, however, determine in Syllis gracilis the serial order of fragmentation, NEW SERIES.-VOL. XIV. NO. 4. MAY, 1927. 
In Procerastea Halleziana, the bud head of the single "stolon," which is formed prior to the sexual reproduction of the species, is always found on Segment 14, the first segment of the first section of three segments.

Similar fragmentation has since been studied in other Syllids, especially in the genus Autolytus, which is closely allied to Procerastea, and an account of this work is given in the present paper.

\section{Autolytus macrophthalma (Marenzeller).}

Fragmentation according to a definite law is shown with special clearness in this species, and has been produced in a large number of specimens by treating them with distilled water on a glass slide in the way described for Procerastea. The breaking-points are quite clear long before an actual rupture takes place.

The two following examples observed on February 19th and 20th, 1923, respectively, are typical of many others :-

$$
\begin{aligned}
& \text { Feb. 19. } \mathrm{H} 7+2+2+2+3+3+3+4+4+4+4+4+3+3+4+4+4 \\
& +4+4+4+4+4+4+11 \mathrm{P} \text {. }
\end{aligned}
$$

Feb. 20. $\mathrm{H} 7+2+2+2+3+3+3+4+4+4+4+4+3+3+4+4+4$

$$
+4+4+4+4+4+4+6 \text { P. }
$$

The bud head in all cases forms on Segment 14.

Autolytus macrophthalma is a much longer species than Procerastea Halleziana, and contains many more segments. A large specimen of A. macrophthalma may have from 90 to 100 segments, whereas a large Procerastea seldom has more than 50 to 60 .

It will be seen that for the first portion of the body the sequence of breaking-points is the same in the two worms, viz. the head and seven segments, three sections of two segments, three sections of three segments, five sections of four segments. Procerastea then continues with sections of three segments, which persist until the undividing segments in front of the tail are reached. Autolytus macrophthalma, on the other hand, has only two sections of three in this position, and then continues with sections of four. These two sections of three, interpolated in the midst of the sections of four, are remarkably constant in this species, and are invariably in the same position, that is, they are segments 43 to 48 .

It is interesting that in $A$. macrophthalma the positions at which the breaks occur are in many specimens clearly visible as thin, transverse, transparent lines in the living animal, before it has been treated with

so that we do not know whether it resembles that found in Procerastea and in other Syllids to be described in the present paper. Since the publication of my Procerastea paper Dehorne (Comptes rendus, t. 178, 1924, p. 143) has described asexual reproduction in Dodecaceria. 
distilled water at all. The worm is of a light yellow colour, except for the rose-coloured proventriculus, but the amount of yellow pigment is very slight. Nevertheless its absence along the lines where the fragmentation occurs gives rise to the distinct transparent lines by which the body is crossed.

Interesting variations in the breaking up of A. macrophthalma are seen in a specimen treated with distilled water on February 19, 1923, which gave the following formula :-

$$
\begin{gathered}
\mathrm{H} 7+2+1+2+2+2+3+3+3+4+4+4+4+4+3+3+4+4+4+4+4 \\
+4+4+4+8 \mathrm{P},
\end{gathered}
$$

and one on March 6, 1923, which gave :-

$$
\begin{gathered}
\mathrm{H} 7+2+2+1+2+3+3+3+3+4+4+4+4+4+3+3+4+4+4+4+4 \\
+10 \mathrm{P} .
\end{gathered}
$$

In both cases it looks as if extra segments had been interpolated in the anterior region of the body (the part usually occupied by segments 1 to 13). The phenomenon is probably due to some irregular regeneration after injury.

Experiments on regeneration were not very successful in this species, though not many were tried. The difficulty was due to the fact that the sections did not live well after they had been separated. The only successful pieces were (1) Head and segments 1 to 13 gave in six weeks a posterior regeneration of ten setigerous segments and two well-developed anal cirri ; (2) Segments 20, 21, and 22 (the last section of the first group of threes) gave in six weeks a posterior regeneration with five well-developed and one rudimentary setigerous segments, and well-developed anal cirri, but with no anterior regeneration; (3) Segments 23 to 26 (the first section of four) gave in six weeks a posterior regeneration with three setigerous segments and well-developed anal cirri, but again with no anterior regeneration.

\section{Autolytus pictus (Ehlers).}

This species breaks under the action of distilled water in exactly the same way as $A$. macrophthalma, excepting that the first break occurs behind Segment 9 , that is to say, the first section of 2 is not detached. The following is a typical formula :-

$$
\begin{gathered}
\text { Dec. 18, 1922. } \begin{array}{c}
\mathrm{H} 9+2+2+3+3+3+4+4+4+4+4+3+3+4+4 \\
+4+4+4+4+1+3+5 \mathrm{P} .
\end{array}
\end{gathered}
$$

As in Procerastea the stolon head always occurs on Segment 14. This species is exceptional amongst British species of Autolytus, on account of its deep pigmentation and definite colour pattern (Fig. 1). The dorsal 
surface is covered with a deep deposit of black or dark brown pigment, with the exception of a mid-dorsal longitudinal line (immediately over the intestine), which is free of pigment and hence appears white, and a series of transverse bands free of pigment and hence also appearing white (Fig. 1). We find here in a much more marked and striking form the phenomenon which we have already described in A. macrophthalma, namely, that it is precisely along these pigment free white bands that the breaking-points occur when the worm is treated with distilled water.

The following formula shows the positions of the white bands on a specimen of Autolytus pictus, the + sign showing the position of a band before the worm was broken up :-

$$
\mathrm{H} 7+2+2+2+3+3+3+4+4+4+4+3+1+3+3+4+4+\ldots .
$$

When this worm broke up on the addition of distilled water it gave the following, the + sign now indicating the places where the breaks occurred :-

$$
\begin{gathered}
\mathrm{H} 9+2+2+3+3+3+4+4+4+4+3+1+3+3+4+4+4+3+3+3 \\
+3+4 \mathrm{P} .
\end{gathered}
$$

This case was specially interesting because the exceptional splitting up of the last (fifth) four of the first group of fours into $3+1$ was shown equally clearly by the white bands and by the actual breaks.

The series of facts just described suggests that tissue at the breaking places possesses some definite difference in its chemical properties, which prevents the dark pigment deposited on the rest of the back from being laid down.

It may be mentioned that the pigment is a highly resistant substance, being insoluble in water, in alcohol, in ether following treatment with absolute alcohol, and in strong hydrochloric acid.

It was noted that in specimens in which the sexual products were ripening the dark pigment became lighter, somewhat greenish and more diffuse, the white longitudinal band and the white transverse bands becoming much less conspicuous behind Segment 14, the segment upon which the stolon head is budded.

Regeneration in this species takes place much more slowly than in Procerastea, but heads and anterior regeneration have been obtained as well as regeneration of posterior segments. A description of these results is reserved until further experiments have been made.

\section{LEgend to Fig. 1 .}

FIG. 1.-Autolytus pictus (Ehlers). $\quad \times 8 \frac{1}{4}$. The parapodia and setae of the first setigerous segment do not appear in the drawing, as they cannot be seen in a dorsal view of the worm. They lie immediately below the very long dorsal cirri. (From a drawing by Mrs. E. W. Sexton.) 


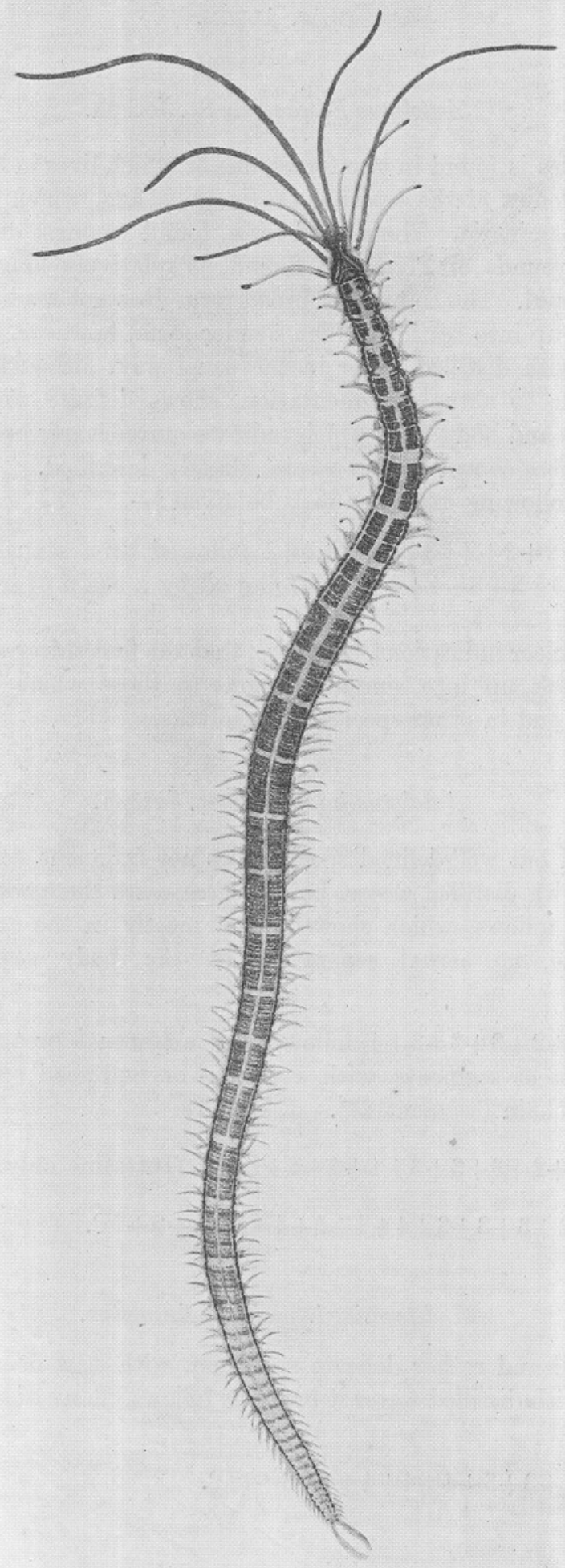

FIG. 1. 


\section{Autolytus Edwarsi de St. Joseph.}

This species is found in two forms, one of which lives in large numbers amongst colonies of the hydroid Obelia geniculata, which occurs abundantly on Laminaria. The second form, found amongst dredgings from the outer grounds of Plymouth Sound, is relatively longer and more slender in build. The commoner broad form does not readily show signs of breaking up into sections. The slender form, however, when treated on a slide with distilled water in the usual way, although it does not usually come to actual fragmentation, shows definite constrictions of the intestine and body wall, which indicate quite clearly breaking-points similar to those shown by the species already described.

The two following examples may be given :-

$\mathrm{H} 7+2+2+2+3+3+3+4+4$ followed by a sexual bud.

$\mathrm{H} 11+2+3+3+3+4+4+4+3$ followed by a chain of sexual buds.

There are clear indications, therefore, that the first thirty-four segments tend to break up into similar sections to those which are found in Procerastea and in other species of Autolytus.

\section{Autolytus inermis de St. Joseph.}

This small but well-defined species does not fragment very readily on treatment with distilled water, but in three cases there was a tendency to break as follows, which showed itself mostly in the constriction of the intestine, no actual separation of the body segments being reached :-

1. $\mathrm{H} 9+2+2+3+3+3+4$ followed by an actual breaking off of a chain of segments, with a stolon- or bud-head on the first of the chain (segment 27).

2. $\mathrm{H} 9+2+2+3+3+3+4+4+4+14 \mathrm{P}$. (Intestine only.)

3. $\mathrm{H} 11+2+3+3+3+4+4+4+4+4+3+3+7 \mathrm{P}$.

\section{Undetermined species of Autolytus.}

1. A small and rather delicate specimen, with eggs nearly ripe. On treatment with distilled water it broke as follows, many of the eggs being extruded :-

$$
\mathrm{H} 13+3+3+3+4+4+4+4+3+12 \mathrm{P} .
$$


2. A specimen resembling A. Ehbiensis de St. Joseph, but with no definite teeth on the proboscis gave:-

$$
\mathrm{H} 13+3+3+3+4+4+\text { ca. } 12 \mathrm{P} \text {. }
$$

3. A specimen resembling the last, but with about twenty-five equal teeth on the proboscis, gave with the intestine, but with no break or great constriction of the body :-

$$
\mathrm{H} 9+2+2+3+3+3+4+4+\mathrm{a} \text { bud head and ca. } 15 \mathrm{P} \text {. }
$$

4. A specimen which was probably Autolytus prolifer, but the teeth on the proboscis could not be seen clearly enough to be sure that the number was 10 , gave on treatment with distilled water :-

$$
\mathrm{H} 7+2+2+2+3+3+3+4+4+4+4+4+3+3+4+4+4+25 \mathrm{P} .
$$

This is similar to what occurred in A. macrophthalma and A. pictus.

From the observations recorded above it is clear that the tendency to fragment according to a definite scheme is widespread in the genus Autolytus, and that the scheme for the first forty or fifty setigerous segments is the same as that previously described for Procerastea. In the case of the longer members of the genus possessing considerably more than fifty segments a new regularity of fragmentation is continued in the posterior segments, of which the arrangement found in Autolytus macrophthalma is typical.

There is one species of the genus, however, Autolytus rubropunctatus, which, in spite of many attempts, has shown little or no tendency to fragment. The tissue of this worm seems to be tougher and more compact than that of allied species of about the same size.

In the genus Autolytus I have met with no evidence that fragmentation followed by regeneration is a normal process of asexual reproduction occurring in nature, as it certainly is in the genus Procerastea. In no instance have I found worms which appeared to have originated from segments of the body, which were regenerating new anterior and posterior ends. The only cases of obvious regeneration which were seen, and these were not infrequent in Autolytus pictus, were posterior regenerations from old heads and anterior segments, arising generally from the thirteenth setigerous segment, and thus replacing that part of the body which had broken away as the ripe stolon, or free-swimming bud.

Attempts have been made to cause other Syllids to fragment by the addition of distilled water. Positive results were obtained for the two following species :-

Syllis (Pionosyllis) lamelligera de St. Joseph. 
This gave quite distinctly :-

$$
\mathrm{H} 9+2+2+3+3+3+4+3+4+2+2+6 \text { P. }
$$

Syllis (Pionosyllis) divaricata Keferstein.

$$
\mathrm{H} 9+4+3+3+3+4+5+3+4+4+4+5 \mathrm{P} .
$$

There were signs that regeneration had occurred after the section of 5 (i.e. after the thirty-first setigerous segment).

No sign of fragmentation on addition of distilled water was found in the following Syllids: Odontosyllis ctenostoma Claparède, Syllis (Typosyllis) armillaris (Müller), Trypanosyllis zebra (Grube), Syllides longocirrata Oersted, Myrianida pinnigera (Montagu).

My best thanks are due to Mrs. E. W: Sexton for the figure of Autolytus pictus. 